\title{
Una valoración personal acerca de la impunidad y la declaración de inconstitucionalidad de las Ilamadas Leyes del Perdón, Punto Final y Obediencia Debida en la Argentina*
}

Marcelo Alberto López Alfonsín**

http://dx.doi.org/10.21503/lex.v9i8.396

* Ponencia presentada al IV Encuentro Internacional de Asociaciones de Derecho Constitucional, Uruguay, Montevideo, durante el 17 y 18 de junio de 2011.

** Abogado, egresado de la Universidad de Buenos Aires. Realizó una Maestría en Ambiente Humano en la UNLZ y es candidato doctoral de la Universidad de Buenos Aires. Actualmente se desempeña como profesor de grado y postgrado en la Universidad de Buenos Aires, la Universidad Nacional del Litoral, y la Universidad Católica de la Plata, entre otras. Es docente-Investigador del Programa Interdisciplinario de la Universidad de Buenos Aires sobre Cambio Climático. 



\section{Introducción}

Durante los años setenta, América Latina sufrió una época caracterizada por las dictaduras militares y las violaciones a los Derechos Humanos. A partir de mediados de los años ochenta, diversas transiciones democráticas, según los rasgos propios de cada sociedad, se iniciaron en nuestros países. Todas tenían como afán común consolidar el régimen democrático y realizar una búsqueda de verdad y justicia. Así, cada país avanzó hasta donde sus fuerzas sociales y políticas encontraron sus propios límites en resguardo de su memoria colectiva y de su propia conciencia ciudadana. Mucho tuvo, y tiene, que ver con este camino, el papel jugado por el Sistema Interamericano de Protección de los Derechos Humanos, adoptado a través del conocido Pacto de San José de Costa Rica, y, en especial, los roles desempeñados por sus órganos de protección: la Comisión y la Corte Interamericana de Derechos Humanos.

De diferentes formas, este camino fue realizado por los tres poderes constitucionales en cada Estado. El presente trabajo tiene como finalidad describir las actitudes de estos protagonistas en la transición democrática en la Argentina a partir del 10 de diciembre de 1983 a la fecha, sin perder de vista la perspectiva propia de las teorías de la ciencia política y del derecho constitucional. Deseamos dejar en claro nuestra posición contra la impunidad, así como afirmar el respeto a los derechos fundamentales, como pilares del sistema republicano, dentro de lo que la Constitución de España de 1978 define con precisión como el "Estado Social y Democrático de Derecho", a cuyo paradigma nos adscribimos sin cortapisas.

\section{Las violaciones a los Derechos Humanos en la Argentina y la Ley de Autoamnistía del último gobierno militar}

Como muy bien señala Ernesto Sábato en el prólogo del "Nunca más":

1 Informe de la Comisión Nacional sobre la Desaparición de Personas - CONADEP. EUDEBA, Setiembre de 1984. 
Durante la década del setenta, la Argentina fue convulsionada por un terror que provenía tanto desde la extrema derecha como de la extrema izquierda, fenómeno que ha ocurrido en muchos otros países. Así aconteció en Italia que, durante largos años, debió sufrir la despiadada acción de las formaciones fascistas, de las Brigadas Rojas y de grupos similares. Pero esa nación no abandonó en ningún momento los principios del derecho para combatirlos, y lo hizo con absoluta eficacia mediante los tribunales ordinarios, ofreciendo a los acusados todas las garantías de la defensa en juicio; y en ocasión del secuestro de Aldo Moro, cuando un miembro de los servicios de seguridad le propuso al General Della Chiesa torturar a un detenido que parecía saber mucho, le respondió con palabras memorables: 'Italia puede permitirse perder a Aldo Moro. No, en cambio, implantar la tortura' (...) No fue de esta manera en nuestro país: a los delitos de los terroristas, las Fuerzas Armadas respondieron con un terrorismo infinitamente peor que el combatido, porque desde el 24 de marzo de 1976 contaron con el poderío y la impunidad del Estado absoluto, secuestrando, torturando y asesinando a miles de seres humanos.

Esta metodología del terrorismo de Estado fue implacablemente descrita por el Informe de la Comisión Interamericana de Derechos Humanos aprobado por la Asamblea General de la Organización de Estados Americanos (OEA) en su sesión del 11 de abril de 1980. A la luz de los antecedentes recabados en ocasión de su visita a la Argentina durante el mes de setiembre de 1979, la Comisión concluye que, durante el período $1975-1979,{ }^{2}$ las autoridades públicas y sus agentes cometieron numerosas y graves violaciones de derechos fundamentales reconocidos en la Declaración Americana de Derechos y Deberes del Hombre adoptada por la OEA el 2 de mayo de $1948 .^{3}$

Sin embargo, el último gobierno militar impuesto con posterioridad a la derrota frente a Gran Bretaña en $1982^{4}$ sancionó su propia Ley de Autoanmistía No 22.924 , autodenominada de "pacificación nacional" y repudiada mayoritariamente por el movimiento de derechos humanos y los partidos políticos que participarían de las elecciones del 30 de octubre de 1983, con excepción del Partido Justicialista, cuyo candidato presidencial -ítalo-argentino, Luder-se pronunció a favor de su vigencia durante el desarrollo de la campaña electoral.

La violencia política en la Argentina se acentuó a partir de la muerte del General Juan Domingo Perón el $1^{\circ}$ de Julio de 1974.

Informe de la Comisión Interamericana de Derechos Humanos, 667o sesión, 49 período, Asamblea de la OEA.

Cf.: Enrique Vázquez. La última. Origen, apogeo y caída de la dictadura militar. Eudeba: 1985.

Publicada en el Boletín Oficial el 27 de setiembre de 1983. 
El triunfo de la Unión Cívica Radical hizo que, una vez asumido como Presidente de la República el 10 de diciembre de $1983^{6}$, Raúl Ricardo Alfonsín enviara un proyecto de ley derogando dicha normativa de facto, iniciativa que fue respaldada por unanimidad del Congreso de la Nación a través de la Ley No 23.0407. Dice su texto:

ARTICULO $1^{\mathbf{0}}$ - Derógase por inconstitucional y declárase insanablemente nula la ley de facto No 22.924 .

ARTICULO $2^{\circ}$ - La ley de facto No 22.924 carece de todo efecto jurídico para el juzgamiento de las responsabilidades penal, civil, administrativa y militar emergentes de los hechos que ella pretende cubrir, siendo en particular inaplicable a ella el principio de la ley penal más benigna establecido en el artículo $2^{\circ}$ del Código Penal. ${ }^{8}$ Lo dispuesto en el párrafo anterior no se altera por la existencia de decisiones judiciales firmes que hayan aplicado la ley de facto No 22.924 .

ARTICULO $3^{\circ}$ - La persona que hubiera recuperado su libertad por aplicación de la ley de facto No 22.924 deberá presentarse ante el tribunal de radicación de la causa dentro del quinto (5) día de la vigencia de la presente ley. En caso contrario, será declarada rebelde y se dispondrá su captura, sin necesidad de citación previa. Si se tratare de un civil sometido a la jurisdicción militar, la presentación a que se refiere el párrafo anterior podrá hacerse efectiva simultáneamente con la impugnación dirigida contra ese enjuiciamiento, y en el tribunal donde esta impugnación se radique.

ARTICULO $4^{\mathbf{0}}$ - En los casos expuestos en el artículo $3^{\circ}$, la eximición de prisión y la excarcelación serán procedentes, sin necesidad de que concurran los requisitos establecidos en el artículo 379 del Código de Procedimientos en Materia Penal, a menos que existan motivos para presumir que el imputado intentará eludir la acción de la justicia. El tribunal interviniente, si hace lugar a la libertad bajo caución, podrá imponer al imputado, además de las obligaciones a que se refiere el artículo 386 del Código de Procedimientos en Materia Penal, la de presentarse periódicamente al tribunal, o a la dependencia policial más próxima a su domicilio real. La resolución que haga lugar a la libertad bajo caución, y la que imponga la obligación mencionada en el párrafo precedente, no serán apelables. La que deniegue la libertad bajo caución será apelable en relación en el plazo de tres (3) días.

\footnotetext{
Fecha por demás simbólica, pues es la que conmemora el Día Universal de los Derechos Humanos. Boletín oficial del 29 de diciembre de 1983.

Cf.: NINO, Carlos Santiago. Juicio al mal absoluto. Los fundamentos y la historia del juicio a las juntas del Proceso, Emecé: Buenos Aires, 1997.
} 
Comenzaba así un camino de reparación y de búsqueda de verdad y justicia que se consolidó con los decretos No 157 -que iniciaba las acciones penales contra los principales responsables del terrorismo de Estado- y No 158 -que hacía lo mismo contra las cúpulas de las organizaciones armadas conocidas como Montoneros y el Ejército Revolucionario del Pueblo (ERP) -, así como la creación de la Comisión Nacional sobre la Desaparición de Personas. Este es el marco dentro del cual analizaremos, a continuación, la actividad de los tres poderes del Estado, ya reconquistada la plena validez y vigencia de la Constitución histórica de 1853/ 60.

\section{El informe de la CONADEP y el juicio a las juntas militares. Las llamadas "leyes del perdón"}

A partir de los tres actos del Poder Ejecutivo al inicio de la transición democrática, resulta evidente cuál fue la voluntad política del mismo, al igual que la actitud del Poder Legislativo respecto de un uso infrecuente de control de constitucionalidad en un sistema que adoptó el modelo judicial difuso a partir del caso "Sojo", en sintonía con el célebre antecedente norteamericano "Marbury vs. Madison" (1803).

La CONADEP carecía de funciones judiciales, solamente recibió denuncias y elaboró un informe final que entregó al Presidente de la Nación. Este sirvió como principal antecedente para la acusación del Ministerio Público en las causas iniciadas en virtud de los decretos No 157 y 158 antes referidos.

Tal como señala el prólogo del "Nunca más":

Nuestra Comisión no fue instituida para juzgar, pues para eso están los jueces constitucionales, sino para indagar la suerte de los desaparecidos en el curso de estos años aciagos de la vida nacional. Pero, después de haber recibido varios miles de declaraciones y testimonios, de haber verificado o determinado la existencia de cientos de lugares clandestinos de detención y de acumular más de cincuenta mil páginas documentales, tenemos la certidumbre de que la dictadura militar produjo la más grande tragedia de nuestra historia, y la más salvaje.

Dicha comisión fue integrada por personalidades de reconocida trayectoria cívica, seleccionadas con un marcado pluralismo ideológico y religioso, y su labor fue acompañada por tres representantes de la Cámara de Diputados de la Nación. ${ }^{9}$ El informe final producido es un orgullo para cualquier demócrata del mundo y un modelo de lucha cívica ejemplar. ${ }^{10}$

\footnotetext{
Los tres diputados nacionales pertenecían al bloque parlamentario de la Unión Cívica Radical, pues el Partido Justicialista declinó de nominar sus representantes e impuso su mayoría parlamentaria en el Senado de la Nación para que este cuerpo no integrara la Conadep.

10 Quiero destacar que similar orgullo me produjo la lectura del "Hatun Willakuy", versión abreviada del Informe final de
} 
Mayor orgullo aún es el que me impone la sola mención del histórico juicio a las juntas militares ${ }^{11}$ que se impulsó siguiendo la recomendación final del llamado "Informe Sábato":

Las grandes calamidades son siempre aleccionadoras, y sin duda el más terrible drama que, en toda su historia, sufrió la Nación servirá para hacernos comprender que únicamente la democracia es capaz de preservar a un pueblo de semejante horror, que sólo ella puede mantener y salvar los sagrados y esenciales derechos de la criatura humana. Únicamente así podremos estar seguros de que NUNCA MAS en nuestra patria se repetirán hechos que nos han hecho trágicamente famosos en el mundo civilizado.

Este proceso se llevó a cabo por avocación de la justicia civil ante la renuencia del Consejo Supremo de las Fuerzas Armadas, recién después de que la Corte Suprema de Justicia de la Nación considerara constitucional la Ley No 23.040 en el caso "Videla I" en el mes de diciembre de 1984, y culminó con la imposición de severas sanciones a los máximos responsables políticos del plan de aniquilamiento llevado adelante bajo la forma de terrorismo de Estado.

Las condenas impuestas por la Cámara Nacional de Apelaciones en lo Criminal y Correccional Federal fueron en su totalidad revisadas nuevamente por la Corte Suprema de Justicia de la Nación y el proceso judicial en su conjunto, ratificado en su última instancia en el caso "Videla II" en el mes de diciembre de 1985.

A partir de estos históricos pronunciamientos, los tribunales inferiores del Poder Judicial tomaron un fuerte y activo impulso en relación con otros integrantes de las fuerzas armadas de menor jerarquía, lo cual originó un profundo malestar entre los militares y una amenaza muy fuerte ante la fragilidad de la democracia reconquistada en 1983. Esto impulsó al presidente Alfonsín a presentar una iniciativa parlamentaria que ponía un "punto final" a la persecución penal sobre estos oficiales y suboficiales que participaron de la represión, a través de un plazo de caducidad expreso en las causas que se venían llevando adelante. El Congreso de la Nación sancionó, en el mes de diciembre de 1986, la Ley No $23.492^{12}$, la cual en su artículo $1^{\circ}$ dispuso:

Se extinguirá la acción penal respecto de toda persona por su presunta participación en cualquier grado, en los delitos del artículo 10 de la Ley 23.04913, que no estuviere prófugo, o declarado en rebeldía, o que haya sido ordenada su

la Comisión de la Verdad y Reconciliación del Perú.

11 También se impulsó un juicio por las responsabilidades militares de los tres comandantes en jefe de las fuerzas armadas que dirigieron la derrota militar por la guerra de Malvinas entre el 2 de abril y el 14 de junio de 1982.

12 Publicada en el Boletín Oficial, el 29 de diciembre de 1986.

13 Se refiere al Código de Justicia Militar. 
citación a prestar declaración indagatoria por tribunal competente, antes de los sesenta días corridos a partir de la fecha de promulgación de la presente ley". Sólo se exceptuaron de esta disposición los casos de "delitos de sustitución del estado civil y sustracción y ocultación de menores (artículo 5º).

Este plazo -sumamente restrictivo - aceleró el activismo judicial y, una vez cumplido el lapso indicado, eran cerca de 2.000 las causas judiciales que permanecían en trámite, en contra del objetivo político señalado. Se buscó atenuar el error con instrucciones a los responsables del ministerio público para limitar el número de imputados, lo cual fue profundamente rechazado por la sociedad civil.

La debilidad del gobierno se vio patentemente demostrada en los episodios de la Semana Santa de 1987, al negarse un oficial de menor jerarquía a presentarse ante una citación judicial y recibir el apoyo de un importante sector militar -conocido como los "carapintadas"- sin la condigna represión por parte de sus superiores. Indudablemente, esto aceleró la búsqueda de otra solución legislativa, y así el Poder Ejecutivo envió al Congreso de la Nación un proyecto de ley que éste sancionó en el mes de junio de 1987, conocido como "obediencia debida". La Ley No $23.521{ }^{14}$ estableció en su artículo $1^{\circ}$ :

Se presume sin admitir prueba en contrario que quienes a la fecha de la comisión del hecho revistaban como oficiales jefes, oficiales subalternos, suboficiales y personal de tropa de las fuerzas armadas, de seguridad, policiales y penitenciarias, no son punibles por los delitos a que se refiere el artículo 10, punto 1 de la Ley No $23.049^{15}$ por haber obrado en virtud de obediencia debida (...) En tales casos se considerará de pleno derecho que las personas mencionadas obraron en estado de coerción bajo subordinación a la autoridad superior y en cumplimiento de órdenes, sin facultad o posibilidad de inspección, oposición o resistencia a ellas en cuanto a su oportunidad y legitimidad”. En tanto, el artículo $2^{\circ}$ enunció: "La presunción establecida en el artículo anterior no será aplicable respecto de los delitos de violación, sustracción y ocultación de menores o sustitución de su estado civil y apropiación extorsiva de inmuebles". Por último, el artículo 40 prescribió: "Sin perjuicio de lo dispuesto por la Ley 23.492, en las causas respecto de las cuales no hubiera transcurrido el plazo previsto en el artículo $1^{\circ}$ de la misma, no podrá disponerse la citación a prestar declaración indagatoria de las personas mencionadas en el artículo $1^{\circ}$, primer párrafo de la presente ley.

\footnotetext{
Publicada en el Boletín Oficial, el 9 de junio de 1987.

Ver nota 13.
} 
Personalmente, me he manifestado en más de una ocasión en contra de estas leyes conocidas como "punto final" y "obediencia debida". Mi postura siempre se mantuvo en consonancia, desde la perspectiva política, con la convicción de que la transición democrática no era fortalecida sino debilitada con estas decisiones legislativas. Pero he reproducido el texto de las normas para que quede claro su naturaleza jurídica: la primera es una ley de caducidad de la pretensión punitiva del Estado, y la segunda es una definición de los límites de imputabilidad en materia penal en relación con las violaciones a los Derechos Humanos ocurridos en el período 1976-1983. Ninguna de las dos implica de por sí impunidad, pues ésta quedó desterrada con la derogación de la ley de autoanmistía militar, y la responsabilidad quedó concentrada judicialmente en los condenados por el juicio a las juntas militares. Es más, al final del gobierno de Alfonsín, estaban en trámite más de 200 causas, y condenados efectivamente más de 40 jefes militares ${ }^{16}$. La impunidad vino después, como lo veremos a continuación.

\section{Los indultos a los procesados y a los condenados por violaciones a los Derechos Humanos. El informe No 28/92 de la Comisión Interamericana de Derechos Humanos}

Creo sinceramente que hablar de impunidad al 9 de julio de 1989, cuando se produce el traspaso al nuevo gobierno del Presidente Carlos Saúl Menem, es una deslealtad. Hemos señalado cuál es -desde nuestra opinión- la naturaleza jurídica de las llamadas "leyes del perdón". Sin embargo, se las pretende mostrar como amnistías. El inicio de la impunidad se da con el dictado del decreto de indulto a los procesados por violaciones a los derechos humanos antes mencionados. ${ }^{17}$ Ahí se produce el giro que el nuevo titular del Poder Ejecutivo le impone a la política en la materia, aún después de que la Corte Suprema de Justicia de la Nación ratificara la constitucionalidad de las leyes No 23.492 y 23.521 en la causa "Camps". ${ }^{18}$

Pero la culminación de la impunidad es consagrada con los decretos del presidente Menem No 2741/90, 2742/90, 2743/90. ${ }^{19}$ Dichas normas dispusieron la aplicación de los indultos a la totalidad de los jefes militares amparados por las leyes de "punto final" y "obediencia debida", a los acusados de actividades terroristas que se encontraban prófugos, detenidos, excarcelados o condenados, a la totalidad de las fuerzas armadas, de seguridad y de inteligencia que participaron de las rebeliones de Semana Santa de 1987 y de Villa Martelli de 1988 (comandada por el coronel Mohamed Alí Seineldín), a los ex miembros de la junta militar

16 Ver nota 7 y Alfonsín, Raúl Ricardo. Democracia y consenso. Ed. Corregidos: Buenos Aires, 1996.

17 Es el decreto No 1002 del 7 de octubre de 1989. En similar sentido, los decretos No 1001/89, 1004/89 y $1005 / 89$

18 Fallos: 310: 1162. Se repiten sus argumentos en otras 8 sentencias similares de la Corte. Estas son: Falllos: 311:401, 816, 890, 1085 y 1095; 312: 111; 316: 532 y 2171 y 321:2031.

19 Publicados en el Boletín Oficial, el 28 de diciembre de 1990. 
condenados por su responsabilidad militar en la guerra de Malvinas, e incluso a varios civiles involucrados en estos hechos de sublevación contra el primer gobierno democrático. Frente a esta decisión hubo un fuerte rechazo de la sociedad civil y de los partidos políticos -a excepción del Partido Justicialista en el gobierno- pero no hubo marcha atrás en la decisión.

Fue la Comisión Interamericana de Derechos Humanos la que se refirió a la impunidad englobando -desde nuestra visión erróneamente- a las llamadas "leyes del perdón” y a los indultos. Así, este organismo se pronunció de esta manera:

las leyes No 23.492 y 23.561 y el decreto $1002 / 89$ son incompatibles con el artículo XVIII (derecho a la justicia) de la Declaración Americana de Derechos y Deberes del Hombre y los artículos 1, 8 y 25 de la Convención Americana sobre Derechos Humanos. ${ }^{20}$

Esta condena política de la CIDH reabrió el debate sobre la cuestión ${ }^{21}$, pero el salto cualitativo, desde la perspectiva de la protección jurídica de los Derechos Humanos y su fortalecimiento en la dogmática constitucional, se produjo con la reforma constitucional de 1994, que le otorga jerarquía constitucional a numerosos instrumentos internacionales del DIDH en el artículo 75, inciso 22 de la Ley Fundamental. ${ }^{22}$

\section{Las últimas posiciones de los poderes del Estado en relación a la impunidad}

Resulta evidente que este salto cualitativo tiene profundas consecuencias en el sistema de fuentes del derecho constitucional. La Corte Suprema de Justicia de la Nación ya ha reconocido en numerosos fallos este enriquecimiento producido por la introducción del DIDH en la aplicación de la legislación infraconstitucional. Los dos pronunciamientos más trascendentes en la materia son el caso "Arancibia Clavel" del año 2004 y el caso "Simón" del año 2005, en el que se declara la inconstitucionalidad del artículo $1^{\circ}$ de la Ley No 23.492 y de los artículos $1^{\circ}, 3^{\circ}$ y $4^{\circ}$ de la Ley No 23.561. En ambos fallos, se cita el antecedente del caso "Barrios Altos" de la Corte Interamericana de Derechos Humanos, ${ }^{23}$ por lo que cabe hacer algunas consideraciones.

a. El análisis del caso de referencia tiene como marco jurídico los alcances de una ley de autoanmistía dictada en Perú por el régimen del presidente Fujimori en los años ‘90.

20 La Argentina ratificó el Pacto de San José de Costa Rica en el año 1984.

21 Ver Bidart Campos, Germán J. "La República Argentina acusada de violación a derechos humanos del Pacto de San José de Costa Rica”, El Derecho, 150-370, citado por Gil Domínguez, Andrés en su obra: Constitución y derechos humanos. Las normas del olvido en la República Argentina, Ed. Ediar: Buenos Aires, 2004.

22 Cf. Manili, Pablo Luis. El bloque de constitucionalidad. Ed. La Ley: Buenos Aires, 2003.

23 Analizado en la "Revista Argentina de Derecho Constitucional" No 4, Ed. Ediar, Buenos Aires, 2001, ps. 195 y ss. 
b. La normativa señalada como "leyes del perdón" no constituye un ejercicio de la facultad de otorgar anmistías propia del Poder Legislativo.

Estimo muy importante el avance dado por la jurisprudencia de la Corte en relación con la imprescriptibilidad de los crímenes de lesa humanidad. Pero este avance no puede hacerse sobre el menoscabo de otros derechos de larga tradición en el derecho penal y en la dogmática constitucional.

- En el caso "Arancibia Clavel" hay una aplicación retroactiva de la Convención de la ONU sobre la materia a expensas de la garantía de irretroactividad de la ley penal consagrada en el artículo 2 del Código Penal de la Nación.

- En el caso "Simón" se pretende equiparar la derogación de la autoanmistía militar operada con la Ley No 23.040 con la declaración de nulidad de las leyes de "punto final" y "obediencia debida" efectuadas por el Congreso de la Nación ${ }^{24}$ en un ejercicio de control de constitucionalidad ajeno a nuestro sistema judicial difuso.

Entiendo que estos dos errores conceptuales son una capitis diminutio de estos dos históricos pronunciamientos que no deben, sin embargo, hacer palidecer la voluntad de los poderes judicial y legislativo en profundizar la protección de los derechos fundamentales.

\section{A modo de colofón}

El breve recorrido efectuado en el presente trabajo es nada más que un intento de aproximación a una temática que está plenamente vigente en América Latina, y que está, obviamente, teñida de ideología y de posiciones políticas a las que no quise renunciar en ningún momento. Pretende ser un aporte personal al debate con una clara perspectiva del lugar en el que formulamos nuestros juicios. Esta es la forma en que la discusión se enriquece y nos ayuda a madurar individual y colectivamente.

Estimo que la lucha contra la impunidad es la señal de fuego de nuestra transición democrática. Otros países han hecho sus experiencias con sus pro y sus contra, con sus debilidades y sus fortalezas. Pero cada transición -la chilena, la uruguaya, la peruana, por citar sólo algunas de las más ricas para el estudio comparativo- tiene sus corsi e ricorsi.

24 Con fecha 21 de agosto de 2003, se sancionó la Ley No 25.779, la cual declara “insanablemente nulas las leyes 23.492 y 23.521". Esta ley fue promulgada por el Poder Ejecutivo en fecha 2 de septiembre del mismo año. 
Evidentemente, la Argentina vivió, y vive, una crisis que parece sin precedentes. Pero es bueno repasar de dónde arrancamos. Y para ello, el prólogo del "Nunca Más" varias veces citado no debe ser olvidado.

Resulta muy útil, para finalizar este itinerario, la opinión del Procurador como cierre de su dictamen en el caso "Simón":

La República Argentina atraviesa momentos de desolación y fatiga. Es como si un pueblo cansado buscara soluciones trágicas. Se ha deteriorado todo, la funcionalidad de las instituciones, la calidad de la vida, el valor de la moneda, la confianza pública, la fe civil, la línea de pobreza, el deseo de renovar la apuesta cívica. Un Estado que apenas puede proveer derecho, apenas seguridad, apenas garantías, poco tiene que predicar. Y no queremos que la indolencia aqueje nuestra grave tarea porque entonces sí estaremos ante la peor tragedia nacional.

Hago mías estas palabras. 